\title{
FAULT TOLERANT CONTROL FOR FIXED SET-POINT CONTROL NONLINEAR NETWORKED CONTROL SYSTEMS
}

\author{
Liu Xiuzhi, Dai Yaping
}

Original scientific paper

This paper proposes an approach for achieving fault tolerant control algorithm for a kind of networked control system which is fixed set-point control and with nonlinear plant. We firstly describe the nonlinear networked control system and linearize the model of the plant at the operating point, then construct a synthesis model of the whole system, which includes all relevant factors in our research such as network induced time delay, data packet loss, the faults of sensors and actuators etc. Based on this model, the stability condition in meaning square sense of the system is gained by constructing a Lyapunov function. Then the fault tolerant control algorithm is obtained from the stability condition. Lastly, a numerical example is used to prove the validity of the theory.

Keywords: fault tolerant control; fixed set-point control; linearize; nonlinear networked control system

Upravljanje tolerancijom greške za nelinearne umrežene upravljačke sustave s regulatorom s čvrstom zadanom točkom

Izvorni znanstveni članak U radu se predlaže pristup za dobivanje algoritma regulatora koji tolerira grešku za vrstu umreženog upravljačkog sustava koji ima regulator s čvrstom zadanom točkom i nelinearno postrojenje. Najprije opisujemo nelinearni umreženi upravljački sustav te lineariziramo model postrojenja u radnoj točki, zatim konstruiramo spojeni model cijelog sustava koji uključuje sve faktore relevantne za naše istraživanje kao što su kašnjenje inducirano mrežom, gubitak podataka, greške senzora i aktuatora itd. Na temelju ovog modela postignuto je stanje stabilnosti u sustavu konstruiranjem Lyapunove funkcije. Zatim je iz stanja stabilnosti dobiven upravljački algoritam tolerancije greške. Konačno je na numeričkom primjeru dokazana validnost teorije.

Ključne riječi: linearizirati; nelinearni umreženi upravljački sustav; regulator s čvrstom zadanom točkom; regulator s tolerancijom na grešku

\section{Introduction}

Networked control system (NCS) has been used in many fields such as industrial automation, remote control, robots and unmanned aerial vehicle etc., compared with local computer control systems, it has many advantages such as ease of maintenance and installation, large flexibility and low cost. However, because of the limitation of network quality and network bandwidth, many challenges still need to be faced before all the advantages of networked control systems can be exploited to their full extent $[1 \div 4]$. Time delay and data packet loss are major characteristics of the networked control systems $[5,6]$. As a kind of complex computer control system, NCS has been a hot object of the research on control theory $[7,8]$. The interest in the research on fault tolerant control (FTC) of networked control system has been increasing in recent years [9]. As the technology of the computer has gotten fully development, the researches on FTC of NCS only deal with the faults of the sensors and actuators.

Most works of the research on fault tolerant control of networked control system focus on linear systems [10]. A few approaches have been used in controller design for stabilization and performance in NCSs. In literature [11], a distribution-based fault model includes both probabilistic sensors fault and actuators fault, networkinduced delays, packet losses and data distortion is proposed. By using Lyapunov functional approach, the criteria for the exponentially mean square stability are obtained. In [12], fault-tolerant control of networked control systems (NCSs) with random actuator failure is studied. Based on the Lyapunov-Krasovskii function, theorems are proved in the study for the system stability and controller design. The problem of fault-tolerant control for uncertain networked control system (NCS) with packet dropouts and actuator fault is studied in literature [13], the stochastic packet dropouts are considered existing not only between sensor and controller but also between controller and actuator. Thus, the NCS is modelled as Markovian jump linear system with four operation modes, sufficient conditions to ensure that the NCS is stochastically stable and satisfy the guaranteed cost performance is developed. In [14], Net Simplex architecture was used in tolerant control software designing and implementation of NCS. In [15], an observer based fault tolerant control method is proposed for a class of networked control systems with transfer delays. Literature [16] deals with static output feedback $\mathrm{H}_{\infty}$ control of a class of discrete-time networked control systems subject to random failures and random delays. Some researchers have tried to use active fault tolerant control to deal with the problem. In [17], a reconfigurator block for the fault condition is proposed and the performance of the overall system will be equivalent to fault-free system when subjected to the actuator failure. A fault tolerant controller based on PI tracking control is designed by Lina Yao and Bo Peng to make the post-fault probability density function still track the given distribution, based on the fault diagnosis information [18].

There are some researchers who have paid attention to the study of stability analysis and fault tolerant controller design for nonlinear NCSs. In [19, 20], nonlinear networked control systems are approximated by Takegi-Sugeno (T-S) fuzzy model, considering possible faults of sensors and actuators, the Lyapunov functional and the linear matrix inequality (LMI) are applied to develop two new stability conditions. In [21, 22], observer-based fault estimation method is presented for a class of nonlinear networked control systems (NCSs) with 
Markov transfer delays, which is used to construct a fault estimation algorithm. In [23], the study is concerned with the fuzzy $\mathrm{H}_{1}$ non-uniform sampling tracking control problem of non-linear systems described by TakagiSugeno fuzzy systems, considering the stochastic actuator failures. Based on Lyapunov functional approach and stochastic analysis technique, a control design scheme that guarantees the prescribed $\mathrm{H}_{1}$ tracking performance of the nonlinear systems is proposed in terms of linearmatrix inequalities.

Motivated by the above observations, this paper introduces a method for designing a fault tolerant controller for the nonlinear networked control system which is fixed set-point control. We firstly linearize the plant model at the desired working point, and then construct the synthesis model of the whole system, which includes time delay, data packet loss, and faults of sensors and actuators. We assume that the time delay is shorter than sampling period, look at data packet loss as Bernoulli process, and use diagonal matrix to describe the working condition of sensors and actuators. The criteria for meaning square stability of the whole system is proposed by constructing a Lyapunov function, by the criteria, the fault tolerant control algorithm can be obtained.

The paper is organized as follows. NCS and faults background representation is given in section 2 . Modelling of the system incorporating time delay, packet loss and sensors and actuators' working condition is accomplished in Section 3. Section 4 gives the stability analysis of the closed-loop system and presents stability condition in the meaning square. A simulation example is used to illustrate the effectiveness of the theoretical results in section 5. Conclusions are given in section 6 .

\section{Background}

The structure of the networked control system considered in this paper is shown in Fig. 1. For the limitation of the equality and bandwidth of the network, there exist time delays and packet loss in both sensor-tocontroller (S-C) channel and in controller-to-actuator (CA) channel.

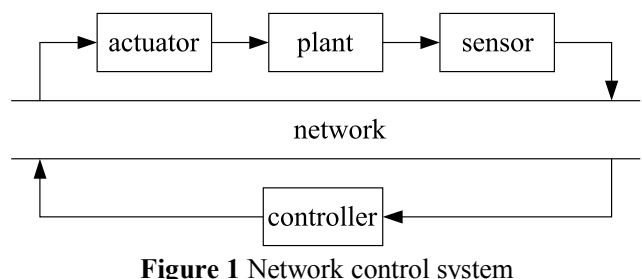

Time delay can be represented by the following variables: $\tau_{\mathrm{sc}}$ : S-C channel delay, $\tau_{\mathrm{ca}}$ : C-A channel delay, $\tau_{k}=\tau_{\mathrm{sc}}+\tau_{\mathrm{ca}}$ : total network induced delay. For data packet loss, we can describe it by two random variables $\theta_{k}$ and $\varphi_{k}$, their values are shown as (1) and (2), and both variables are independent of each other.

$\theta_{k}= \begin{cases}1 & \text { data packet loss in S-C chanel at moment } k T \\ 0 & \text { no packet loss in S-C chanel at moment } k T\end{cases}$ $\varphi_{k}= \begin{cases}1 & \text { packet loss in C-A chanel at moment } k T \\ 0 & \text { no packet loss in C-A chanel at moment } k T\end{cases}$

$$
\text { Let } p_{1}=\lim _{n \rightarrow \infty} \frac{1}{n} \sum_{k=1}^{n} \theta_{k}, p_{2}=\lim _{n \rightarrow \infty} \frac{1}{n} \sum_{k=1}^{n} \varphi_{k} \text {, then } p_{1}, p_{2}
$$

represent the probability of data packet loss in S-C channel and C-A channel respectively. Usually, because two channels are via the same network, we have $p_{1}=p_{2}=p$ and call $p$ as packet loss rate (PLR).

We consider the networked control system with the plant shown as (3)

$\dot{x}=f(x)+g(x) u$ $y=h(x)$

Among them $x, y$ and $u$ represent the state vector, output and control input respectively. $f, g$ and $h$ are nonlinear functions. Suppose the sample period is $T$, the discrete-time model of the plant is shown as (4), $f^{\prime}$ and $g^{\prime}$ are nonlinear function determined by $f, T$ and $g, T$ respectively.

$$
\begin{aligned}
& x(k+1)=f^{\prime}(x(k)) x(k)+g^{\prime}(x(k)) u(k) \\
& y(k)=h(x(k))
\end{aligned}
$$

Assume: (1) the networked induced time delay $\tau_{k}$ is less than the sample period $T$. (2) sensors are time driven and controller and actuators are event driven.

The control input of the plant between $k T$ and $(k+1) T$ is described as (5),

$u(t)=\left\{\begin{array}{cc}u(k) & t \in[k T+\tau,(k+1) T) \\ u(k-1) & t \in[k T, k T+\tau)\end{array}\right.$

Then the discrete model of the closed-loop system is shown as (6).

$$
\begin{aligned}
& x(k+1)=f^{\prime}(x(k)) x(k)+g_{1}^{\prime}(x(k)) u(k)+g_{2}^{\prime}(x(k)) u(k-1) \\
& y(k)=h(x(k))
\end{aligned}
$$

Among them, $g_{1}^{\prime}$ and $g_{2}^{\prime}$ are determined by $g^{\prime}, \tau$ and $T$.

Let $\hat{u}(k), u(k), \hat{x}(k)$ and $x(k)$ represent the plant's input, controller's output, controller's input, plant's state at moment $k T$ respectively. Suppose that the data is transmitted by single packet, then (7) is right.

$$
\left\{\begin{array}{l}
\hat{x}(k)=\left(1-\theta_{k}\right) x(k)+\theta_{k} \hat{x}(k-1) \\
\hat{u}(k)=\left(1-\varphi_{k}\right) u(k)+\varphi_{k} \hat{u}(k-1)
\end{array}\right.
$$

Employing state feedback control, the control input is shown as (8).

$\hat{u}(k)=\left(1-\varphi_{k}\right) c(\hat{x}(k))+\varphi_{k} \hat{u}(k-1)$

Taking both time delay and packet loss into account, we get the model of the closed-loop system as (9).

$$
\begin{aligned}
x(k+1)= & f^{\prime}(x(k)) x(k)+g_{1}^{\prime}(x(k)) c\left(\left(1-\varphi_{k}\right)\left(1-\theta_{k}\right) c(x(k))+\right. \\
& \left.+\left(1-\varphi_{k}\right) \theta_{k} c(\hat{x}(k-1))+\varphi_{k} \hat{u}(k-1)\right)+g_{2}^{\prime}(x(k) u(k-1)
\end{aligned}
$$


As $\theta_{k}$ and $\varphi_{k}$ are random variables $f^{\prime}, g_{1}^{\prime}$ and $g_{2}^{\prime}$ are nonlinear functions, this results in the model being too complex so that it is uneasy in designing the control algorithm for the system, so a new model is needed.

Now we consider the faults of sensors and actuators. Sensors and actuators are two major parts of the whole system, sensors detect the plant's state and transport it to the controller via network, if sensors fail or partly fail, then the plant's state will not be sent to the controller successfully, which will result in the whole system being unable to work properly and even in making the system to be in danger. Actuators also play important roles in keeping the system working properly, their task is to put control algorithm into practice. In order to avoid the danger when some sensors or actuators are in failure, we should design controller that can make the system keep in stability when sensors and actuators are either in normal or in failure state. And firstly we should describe the faults with mathematical method.

Assume the system has $n$ sensors used to detect $n$ working state of the plant, and we construct matrix $\boldsymbol{M}$ shown as (10).

$$
\boldsymbol{M}=\operatorname{diag}\left(\begin{array}{llll}
m_{1} & m_{2} & \cdots & m_{n}
\end{array}\right)
$$

Among them, $m_{i}=\left\{\begin{array}{c}1 \\ {[0,1) \text { the } i^{\text {th }} \text { the } i^{\text {th }} \text { sensor is normal is in failure }}\end{array}\right.$, $i=1,2, \ldots, n ; \hat{x}_{i}=m_{i} x_{i}$ is the signal that is brought to the controller by the sensor of number $i$. When some sensors are in failure, the working state cannot or can only partly be transported to the controller. The state vector signal used by controller is (11)

$$
\hat{x}(k)=\left(1-\theta_{k}\right) M x(k)+\theta_{k} \hat{x}(k-1)
$$

In the same way, we assume that actuator is $\mathrm{m}$ dimensional, we construct matrix $\boldsymbol{N}$ shown as (12).

$$
\boldsymbol{N}=\operatorname{diag}\left(\begin{array}{llll}
l_{1} & l_{2} & \cdots & l_{m}
\end{array}\right)
$$

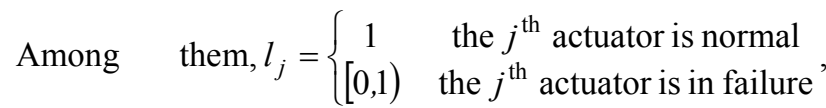
$j=1,2, \ldots, m$. Then real control input at the plant is (13).

$$
\hat{u}(k)=N\left(\left(1-\varphi_{k}\right) K \hat{x}(k)+\varphi_{k} \hat{u}(k-1)\right)
$$

\section{Model of fixed set-point nonlinear networked control system}

When the control system shown by Fig. 1 is fixed setpoint control, and $f$ and $g$ are both smooth functions, suppose $x_{c}$ is system's operating point, the linearized model of the plant at $x_{c}$ is (14)

$$
\dot{x}=F x+G u
$$

Among them,

$$
F=\left[\left.\begin{array}{cccc}
\frac{\partial f_{1}}{\partial x_{1}} & \frac{\partial f_{1}}{\partial x_{2}} & \cdots & \frac{\partial f_{1}}{\partial x_{n}} \\
\frac{\partial f_{2}}{\partial x_{1}} & \frac{\partial f_{2}}{\partial x_{2}} & \cdots & \frac{\partial f_{2}}{\partial x_{n}} \\
\vdots & \vdots & \vdots & \vdots \\
\frac{\partial f_{n}}{\partial x_{1}} & \frac{\partial f_{n}}{\partial x_{2}} & \cdots & \frac{\partial f_{n}}{\partial x_{n}}
\end{array}\right|_{x=x_{c}}, G=g\left(x_{c}\right)\right.
$$

When the sample period is $T$ and the total time delay is $\tau_{k}$, suppose their relation satisfies $\tau_{k}<T$, then the discrete-model of the system is (15).

$x(k+1)=\bar{F} x(k)+G_{1} \hat{u}(k)+G_{2} \hat{u}(k-1)$

Among them, $\bar{F}=\mathrm{e}^{F h}, G_{1}=\int_{0}^{T-\tau_{k}} \mathrm{e}^{F s} G \mathrm{~d} s, G_{2}=\int_{T-\tau_{k}}^{T} \mathrm{e}^{F s} G \mathrm{~d} s$.

Taking time delay, packet loss, sensors and actuators' faults into account, we get the synthesis model of the closed-loop system as (16), $K$ represents feedback gain. Only considering sensor's fault, the model of the closedloop system is (17). In the same way, we get the model of the closed loop system subject to actuator fault only in (18).

$$
\begin{aligned}
& x(k+1)=\left(F+\left(1-\varphi_{k}\right)\left(1-\theta_{k}\right) G_{1} N K \boldsymbol{M}\right) x(k)+ \\
& +\left(1-\varphi_{k}\right) \theta_{k} G_{1} N K \hat{x}(k-1)+\left(G_{1} \varphi_{k}+G_{2}\right) \hat{u}(k-1) \\
& x(k+1)=\left(F+\left(1-\varphi_{k}\right)\left(1-\theta_{k}\right) G_{1} K M\right) x(k)+ \\
& +\left(1-\varphi_{k}\right) \theta_{k} G_{1} K \hat{x}(k-1)+\left(G_{1} \varphi_{k}+G_{2}\right) \hat{u}(k-1) \\
& x(k+1)=\left(F+\left(1-\varphi_{k}\right)\left(1-\theta_{k}\right) G_{1} N K\right) x(k)+ \\
& +\left(1-\varphi_{k}\right) \theta_{k} G_{1} N K \hat{x}(k-1)+\left(G_{1} \varphi_{k}+G_{2}\right) \hat{u}(k-1)
\end{aligned}
$$

Through the analysis above, the synthesis model of the system was established, $x(k)$ represents the plant's state, $\hat{x}(k-1)$ and $\hat{u}(k-1)$ are looked at as the disturbance. If $x(k)$ is convergent with the disturbance work on the system, we can say that the system is stable.

We can also look at the whole system as control object, $x(k), \hat{x}(k-1)$ and $\hat{u}(k-1)$ are all system state, we model the closed-loop system as the following: Let

$$
z(k)=\left[\begin{array}{lll}
x^{\mathrm{T}}(k) & \hat{x}^{\mathrm{T}}(k-1) & \hat{u}^{\mathrm{T}}(k-1)
\end{array}\right]^{\mathrm{T}}
$$

Obviously, $z(k)$ is a state vector of the whole system. We get the expansion model of the system as (20).

$z(k+1)=\Phi_{k} z(k)$

Among them

$$
\begin{aligned}
\Phi_{k} & =\left[\begin{array}{ccc}
\bar{F}+\left(1-\varphi_{k}\right)\left(1-\theta_{k}\right) G_{1} N K M & \left(1-\varphi_{k}\right) \theta_{k} G_{1} N K & \varphi_{k} G_{1}+G_{2} \\
\left(1-\theta_{k}\right) \boldsymbol{M} & \theta_{k} I & 0 \\
\left(1-\varphi_{k}\right)\left(1-\theta_{k}\right) N K M & \left(1-\varphi_{k}\right) \theta_{k} N K & \varphi_{k} I
\end{array}\right]= \\
& =F_{k}+\theta_{k} G_{1 k}+\varphi_{k} G_{2 k}+\varphi_{k} \theta_{k} G_{3 k}
\end{aligned}
$$




$$
\begin{aligned}
F_{k} & =\left[\begin{array}{ccc}
\bar{F}+G_{1} N K M & 0 & G_{2} \\
M & 0 & 0 \\
N K M & 0 & 0
\end{array}\right], G_{1 k}=\left[\begin{array}{ccc}
-G_{1} N K M & G_{1} N K & 0 \\
-M & I & 0 \\
-N K M & N K & 0
\end{array}\right], \\
G_{2 k} & =\left[\begin{array}{ccc}
-G_{1} N K M & 0 & G_{1} \\
0 & 0 & 0 \\
-N K M & 0 & I
\end{array}\right], G_{3 k}=\left[\begin{array}{ccc}
G_{1} N K M & -G_{1} N K & 0 \\
0 & 0 & 0 \\
N K M & -N K & 0
\end{array}\right] .
\end{aligned}
$$

Obviously, (16) is subsystem of (20). When system (20) is stable, system (16) is also stable. So we can design FTC algorithm based on (20) instead of (16).

If we only take the working condition of the sensors into account, then the extension model of the closed-loop system is (21)

$z(k+1)=\Phi_{k M} z(k)$

Among them

$$
\begin{aligned}
\Phi_{k M} & =\left[\begin{array}{ccc}
\bar{F}+\left(1-\varphi_{k}\right)\left(1-\theta_{k}\right) G_{1} K \boldsymbol{M} & \left(1-\varphi_{k}\right) \theta_{k} G_{1} K & \varphi_{k} G_{1}+G_{2} \\
\left(1-\theta_{k}\right) \boldsymbol{M} & \theta_{k} I & 0 \\
\left(1-\varphi_{k}\right)\left(1-\theta_{k}\right) K \boldsymbol{M} & \left(1-\varphi_{k}\right) \theta_{k} K & \varphi_{k} \boldsymbol{I}
\end{array}\right]= \\
= & F_{k \boldsymbol{M}}+\theta_{k} G_{1 k \boldsymbol{M}}+\varphi_{k} G_{2 k \boldsymbol{M}}+\varphi_{k} \theta_{k} G_{3 k M}
\end{aligned}
$$

$F_{k \boldsymbol{M}}=\left[\begin{array}{ccc}\bar{F}+G_{1} K \boldsymbol{M} & 0 & G_{2} \\ \boldsymbol{M} & 0 & 0 \\ K \boldsymbol{M} & 0 & 0\end{array}\right], G_{1 k \boldsymbol{M}}=\left[\begin{array}{ccc}-G_{1} K \boldsymbol{M} & G_{1} \boldsymbol{K} & 0 \\ -\boldsymbol{M} & \boldsymbol{I} & 0 \\ -K \boldsymbol{M} & K & 0\end{array}\right]$,

$G_{2 k M}=\left[\begin{array}{ccc}-G_{1} K \boldsymbol{M} & 0 & G_{1} \\ 0 & 0 & 0 \\ -K \boldsymbol{M} & 0 & I\end{array}\right], G_{3 k \boldsymbol{M}}=\left[\begin{array}{ccc}G_{1} K \boldsymbol{M} & -G_{1} \boldsymbol{K} & 0 \\ 0 & 0 & 0 \\ K \boldsymbol{M} & -K & 0\end{array}\right]$.

In the same way, when we only take the working condition of the actuators into account, we have the extension model of the closed-loop system shown as (22).

$z(k+1)=\Phi_{k N} z(k)$

$$
\begin{aligned}
\Phi_{k N} & =\left[\begin{array}{ccc}
\bar{F}+\left(1-\varphi_{k}\right)\left(1-\theta_{k}\right) G_{1} N K & \left(1-\varphi_{k}\right) \theta_{k} G_{1} N K & \varphi_{k} G_{1}+G_{2} \\
\left(1-\theta_{k}\right) \boldsymbol{I} & \theta_{k} \boldsymbol{I} & 0 \\
\left(1-\varphi_{k}\right)\left(1-\theta_{k}\right) \boldsymbol{N} K & \left(1-\varphi_{k}\right) \theta_{k} N K & \varphi_{k} \boldsymbol{I}
\end{array}\right]= \\
& =F_{k N}+\theta_{k} G_{1 k N}+\varphi_{k} G_{2 k N}+\varphi_{k} \theta_{k} G_{3 k N} \\
F_{k N} & =\left[\begin{array}{ccc}
\bar{F}+G_{1} \boldsymbol{N} K \boldsymbol{M} & 0 & G_{2} \\
\boldsymbol{M} & 0 & 0 \\
\boldsymbol{N} K \boldsymbol{M} & 0 & 0
\end{array}\right], G_{1 k}=\left[\begin{array}{ccc}
-G_{1} \boldsymbol{N} K \boldsymbol{M} & G_{1} \boldsymbol{N} K & 0 \\
-\boldsymbol{M} & \boldsymbol{I} & 0 \\
-\boldsymbol{N} K \boldsymbol{M} & \boldsymbol{N} K & 0
\end{array}\right], \\
G_{2 k} & =\left[\begin{array}{ccc}
-G_{1} \boldsymbol{N} K \boldsymbol{M} & 0 & G_{1} \\
0 & 0 & 0 \\
-\boldsymbol{N} K \boldsymbol{M} & 0 & \boldsymbol{I}
\end{array}\right], G_{3 k}=\left[\begin{array}{ccc}
G_{1} \boldsymbol{N} K \boldsymbol{M} & -G_{1} \boldsymbol{N} K & 0 \\
0 & 0 & 0 \\
\boldsymbol{N} K \boldsymbol{M} & -\boldsymbol{N} K & 0
\end{array}\right] .
\end{aligned}
$$

\section{Stability analysis and fault tolerant control of the system}

In this section, the fault tolerant control of the system mentioned in section 3 is discussed. Firstly, we give some definitions and lemmas as the following.

Definition 1 The system (20) is said to be stabilized in the meaning square sense if Eq. (23) holds for any initial state $z_{0} \in R^{2 n+m}$.

$$
\lim _{k \rightarrow \infty} E\left\{\left\|z_{k}\right\|^{2}\right\}=0
$$

Lemma 1 Assume $x$ and $y$ are both random variables, and they are independent of each other, $E()$ represents the Mathematical expectation function, then (24) holds.

$E(x y)=E(x) E(y)$

Now we analyse the stability condition of the NCS mentioned in section 3, suppose that the packet loss rate is fixed, we have the conclusion as follows:

Theorem 1 For system (20) with the packet loss rate $p$, for any given symmetric positive definite matrix $\boldsymbol{Q}$, if there is a unique symmetric positive solution $P$ to the Eq. (25), then the system is stabilized in the meaning square.

Among them

$\left(F_{k}+p G_{1 k}+p G_{2 k}+p^{2} G_{3 k}\right)^{\mathrm{T}} \boldsymbol{P}\left(F_{k}+p G_{1 k}+p G_{2 k}+p^{2} G_{3 k}\right)-\boldsymbol{P}=-\boldsymbol{Q}$

Proof. The mathematical expectation of state vector $z_{k}$ is $E\left(z_{k}\right)$.

$$
E\left(z_{k}\right)=\left[\begin{array}{llll}
E\left(z_{1 k}\right) & E\left(z_{2 k}\right) & \cdots & E\left(z_{(2 n+m) k}\right)
\end{array}\right]^{\mathrm{T}}
$$

We can get the mathematical expectation of $z_{k+1}$ shown as (27).

$$
\begin{aligned}
& E\left[z_{k+1}\right]=E\left[\left(F_{k}+\theta_{k} G_{1 k}+\varphi_{k} G_{2 k}+\varphi_{k} \theta_{k} G_{3 k}\right) z_{k}\right]= \\
& =E\left[F_{k}+\theta_{k} G_{1 k}+\varphi_{k} G_{2 k}+\varphi_{k} \theta_{k} G_{3 k}\right] E\left[z_{k}\right]= \\
& =\left(F_{k}+p G_{1 k}+p G_{2 k}+p^{2} G_{3 k}\right) E\left[z_{k}\right]
\end{aligned}
$$

$$
V\left(z_{k}\right)=E^{\mathrm{T}}\left(z_{k}\right) \boldsymbol{P} E\left(z_{k}\right)
$$

As $\boldsymbol{P}$ is positive, it is obvious that $V\left(z_{k}\right)$ is positive function and (29) and (30) hold.

$\left.V\left(z_{k}\right)\right|_{z_{k}=0}=0$

$\left.V\left(z_{k}\right)\right|_{z_{k} \rightarrow \infty}=\infty$

$V\left(z_{k}\right)$ is a Lyapunov function of the system (20). Then we have (31) and (32).

Define the function $V$ as (28), 


$$
\begin{aligned}
& V\left(z_{k+1}\right)=E\left(z_{k+1}\right)^{\mathrm{T}} \boldsymbol{P} E\left(z_{k+1}\right)= \\
& =E^{\mathrm{T}}\left[z_{k}\right]\left(F_{k}+p G_{1 k}+p G_{2 k}+p^{2} G_{3 k}\right)^{\mathrm{T}} \boldsymbol{P}\left(F_{k}+p G_{1 k}+p G_{2 k}+p^{2} G_{3 k}\right) E\left[z_{k}\right] \\
& \Delta V=V\left(z_{k+1}\right)-V\left(z_{k}\right)= \\
& =E^{\mathrm{T}}\left[z_{k}\right]\left(F_{k}+p G_{1 k}+p G_{2 k}+p^{2} G_{3 k}\right)^{\mathrm{T}} \boldsymbol{P}\left(F_{k}+p G_{1 k}+p G_{2 k}+p^{2} G_{3 k}\right) E\left[z_{k}\right]-E^{\mathrm{T}}\left[z_{k}\right] \boldsymbol{P} E\left[z_{k}\right]= \\
& =E^{\mathrm{T}}\left[z_{k}\right]\left[\left(F_{k}+p G_{1 k}+p G_{2 k}+p^{2} G_{3 k}\right)^{\mathrm{T}} \boldsymbol{P}\left(F_{k}+p G_{1 k}+p G_{2 k}+p^{2} G_{3 k}\right)-\boldsymbol{P}\right] E\left[z_{k}\right]
\end{aligned}
$$

If there is positive matrix $\boldsymbol{P}$ that makes the matrix matrix $\boldsymbol{Q}_{M}$, if there is a unique symmetric positive $\left(F_{k}+p G_{1 k}+p G_{2 k}+p^{2} G_{3 k}\right)^{\mathrm{T}} \boldsymbol{P}\left(F_{k}+p G_{1 k}+p G_{2 k}+p^{2} G_{3 k}\right)-\boldsymbol{P}$ solution $\boldsymbol{P}_{M}$ to the equation (33), then the system is be negative, then we have $\Delta V<0$, we can conclude that system is stable.

If sensors' faults and actuators' faults are considered individually, the stability condition of the system can be described as the two corollaries as follows.

Corollary1 For system shown as (21) with the packet loss rate is $p$, for any given symmetric positive definite stabilized in the meaning square.

Corollary 2 For system shown as (22) with the packet loss rate is $\mathrm{p}$, for any given symmetric positive definite matrix $\boldsymbol{Q}_{N}$, if there is a unique symmetric positive solution $\boldsymbol{P}_{N}$ to Eq. (34), then the system is stabilized in the meaning square.

$\left(F_{k M}+p G_{1 k M}+p G_{2 k M}+p^{2} G_{3 k M}\right)^{\mathrm{T}} \boldsymbol{P}_{M}\left(F_{k M}+p G_{1 k M}+p G_{2 k M}+p^{2} G_{3 k M}\right)-\boldsymbol{P}=-\boldsymbol{Q}_{M}$

$\left(F_{k N}+p G_{1 k N}+p G_{2 k N}+p^{2} G_{3 k N}\right)^{\mathrm{T}} \boldsymbol{P}_{N}\left(F_{k N}+p G_{1 k N}+p G_{2 k N}+p^{2} G_{3 k N}\right)-\boldsymbol{P}=-\boldsymbol{Q}_{N}$

Remark (1) Fault tolerant controller for a fixed set point nonlinear networked control system can be designed based on theorem 1 or its corollaries. Each feedback gain $K$ obtained in this way is only effective when the system works at the operating point $x_{c}$, when the working point changes, the linearized model of the system changes correspondingly, $K$ should be redesigned. (2) The working point determined by reference input, we should select reference input that can ensure the system work at the desired working pint.

\section{Simulation}

In this section, a numerical example is used to improve the result of our research. Suppose the NCS shown by Fig. 1 with the plant represented by (35).

$$
\begin{aligned}
& \dot{x}_{1}=x_{2} \\
& \dot{x}_{2}=-10 \cdot \sin x_{1}-x_{2}+10 u \\
& y=x_{1}
\end{aligned}
$$

Suppose that network induced time delay $\tau_{k}=18 \mathrm{~ms}$, the packet loss rate $p=0,2$, when the desired output $y=1$, the working point of the system is $x_{1}=1, x_{2}=0$, the linearized model of the plant at the operating point is (36).

$$
\begin{aligned}
& \dot{x}=\left[\begin{array}{cc}
0 & 1 \\
-5,4 & -1
\end{array}\right] \cdot x+\left[\begin{array}{c}
0 \\
10
\end{array}\right] \cdot u \\
& y=\left[\begin{array}{ll}
1 & 0
\end{array}\right] \cdot x
\end{aligned}
$$

We take $T=30 \mathrm{~ms}$, then the discrete model of the plant is (37).

$$
\begin{aligned}
& x(k+1)=\left[\begin{array}{cc}
1,00 & 0,03 \\
-1,16 & 0,97
\end{array}\right] \cdot x(k)+ \\
& +\left[\begin{array}{l}
0,00 \\
0,12
\end{array}\right] \cdot u(k)+\left[\begin{array}{l}
0,004 \\
0,176
\end{array}\right] \cdot u(k-1) .
\end{aligned}
$$

By theorem1, we have the inference input that can make the system working at $x_{1}=1, x_{2}=0$ is $r=4$, because packet loss is random, so we do experiments 6 times at each case, A set of step response curves of $y$ with the sensor in normal condition and in fault condition is shown as Fig. 2 and Fig. 3 respectively.

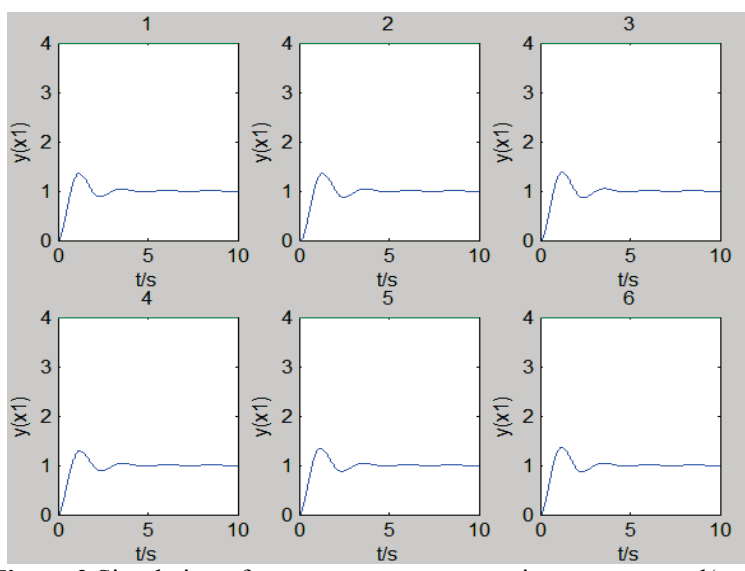

Figure 2 Simulation of system output response in sensor normal $(r=4)$

When the desired output $y=0,5$, the operating point is $x_{1}=0,5, x_{2}=0$, and the linearized model of the plant is (38).

$$
\begin{aligned}
& \dot{x}=\left[\begin{array}{cc}
0 & 1 \\
-8,7 & -1
\end{array}\right] \cdot x+\left[\begin{array}{c}
0 \\
10
\end{array}\right] \cdot u \\
& y=\left[\begin{array}{ll}
1 & 0
\end{array}\right] \cdot x
\end{aligned}
$$


If the model changes, the feedback gain should be redesigned. In the same way, we get $K=[0,170,055], r=3$, and the corresponding step response curves of $y$ with the sensor in normal condition and in fault condition is shown as Fig. 4 and Fig. 5 respectively.

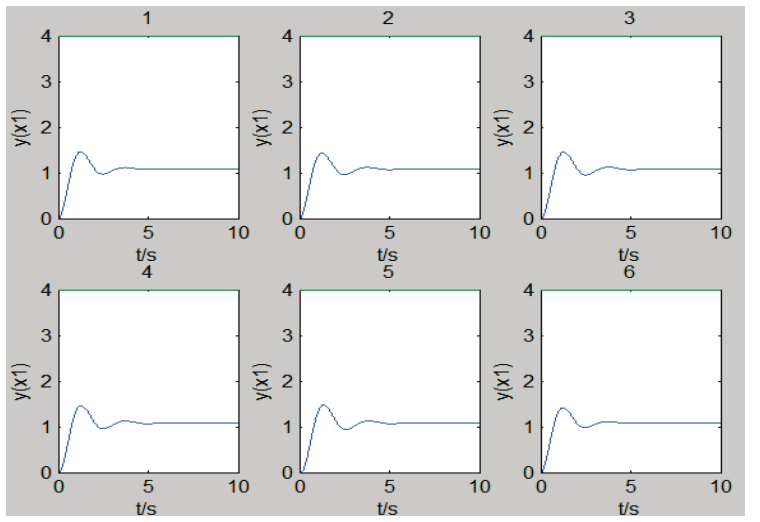

Figure 3 Simulation of system output response in sensor failures $(r=4)$

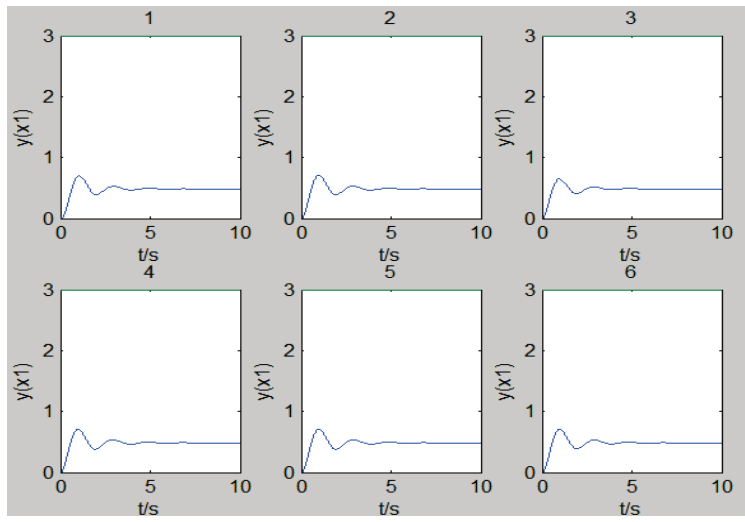

Figure 4 Simulation of system output response in sensor normal $(r=3)$

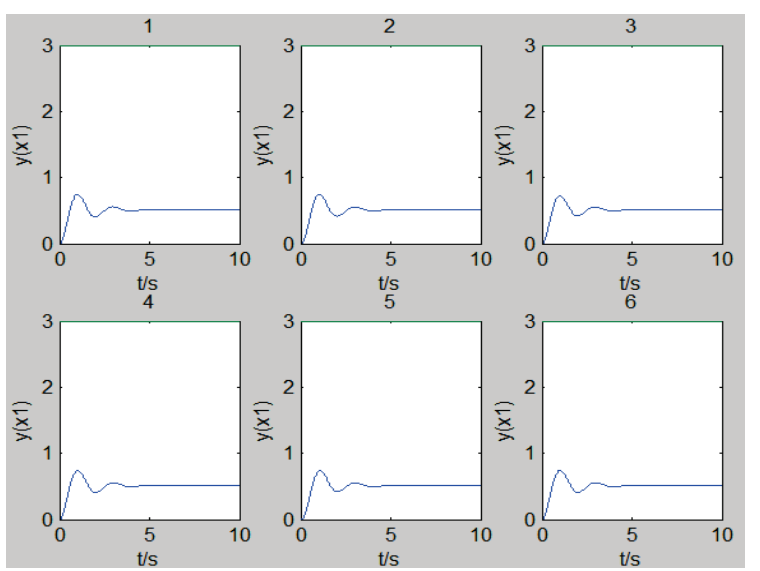

Figure 5 Simulation of system output response in sensor failures $(r=3)$

\section{Conclusion}

This paper is concerned with the fault tolerant control of the networked control systems which is fixed set-point control and with nonlinear plant. Firstly, we construct the model of the whole system. For fixed set-point control system, the states of the system change are near the working point, so we linearized the plant model at the working point of the system, then took the characteristics of network and sensor and actuator fault into consideration, and gained the model of the closed-loop system. Based on this model, the stability condition of the system was gained by constructing a Lypunov function, and the fault tolerant control algorithm that satisfies this condition was gained. Lastly, the correctness and feasibility of the control law was improved by a numerical example.

\section{Acknowledgment}

This work is supported by Program for Changjiang Scholars and Innovative Research Team in University under Grant, China (IRT1208).

\section{Reference}

[1] Gupta, Rachana Ashok; Chow, Mo-Yuen. Networked Control System: Overview and Research Trends. // IEEE Transactions on Industrial Electronics. 57, 7(2010), pp. 2527-2535. DOI: 10.1109/TIE.2009.2035462

[2] Cloosterman, M. B. G.; Hetel, L.; van de Wouw, N.; Heemels, W. P. M. H.; Daafouz, J.; Nijmeijer, H. Controller synthesis for networked control systems. // Automatica. 46, (2010), pp. 1584-1594. DOI: 10.1016/j.automatica.2010.06.017

[3] Kumar, Manoj; Verma, A. K.; Srividya, A.; Marathe, P. P. Developments in Dependability Modeling of Networked Control Systems. // UKACC International Conference on Control /Cardiff, UK, 2012, pp.322-327.

[4] Xu, Hao; Jagannathan, S.; Lewis, F. L. Stochastic optimal control of unknown linear networked control system in the presence of random delays and packet losses. // Automatica. 48, (2012), pp. 1017-1030. DOI: 10.1016/j.automatica.2012.03.007

[5] Zhang, Wen An; Yu, Li. Modelling and control of networked control systems with both network-induced delay and packet-dropout. // Automatica. 44, (2008), pp. 3206-3210. DOI: 10.1016/j.automatica.2008.09.001

[6] Tian, Yu-Chu; Levy, David. Compensation for control packet dropout in networked control systems. // Information Sciences. 178(2008), pp. 1263-1278. DOI: 10.1016/j.ins.2007.10.012

[7] Suzuki, Tatsuo; Kono, Michio; Takahashi, Nobuy; Sato, Osamu. Controllability and stabilizability of a networked control system with periodic communication constraints. // Systems \& Control Letters. 60, (2011), pp. 977-984. DOI: 10.1016/j.sysconle.2011.08.004

[8] Wang, Yu-Long; Han, Qing-Long. Modelling and controller design for discrete-time networked control systems with limited channels and data drift. // Information Sciences. 269, (2014), pp. 332-348. DOI: 10.1016/j.ins.2013.12.041

[9] Yang, Chun-Xi; Guan, Zhi-Hong; Huang, Jian. Stochastic fault tolerant control of networked control systems. // Journal of the Franklin Institute. 346, (2009), pp. 10061020. DOI: 10.1016/j.jfranklin.2009.08.001

[10] Yu, Zhaoxu; Li, Shugang; Du, Hongbin. RazumikhinNussbaum-lemma-based adaptive neural control for uncertain stochastic pure-feedback nonlinear systems with time-varying delays. // International Journal of Robust and Nonlinear Control. 23, (2013), pp. 1214-1239. DOI: 10.1002/rnc.2816

[11] Tian, E.; Yue, D.; Peng, C. Reliable control for networked control systems with probabilistic sensors and actuators faults. // IET Control Theory and Applications. 4, 8(2010), pp. 1478-1488. DOI: 10.1049/iet-cta.2009.0441

[12] Peng, C.; Yang, T. C.; Tian, E. G. Robust fault-tolerant control of networked control systems with stochastic actuator failure. // IET Control Theory and Applications. 4, 12(2010), pp. 3003-3011. DOI: 10.1049/iet-cta.2009.0427 
[13] Xie, Dexiao; Chen, Gang; Zhang, Dengfeng. Guaranteed Cost Fault-tolerant Control for Uncertain Networked Control System with Packet Dropouts. // Proceeding of the IEEE International Conference on Automation and Logistics / Zhengzhou, China, 2012, pp. 35-40. DOI: 10.1109/ical.2012.6308166

[14] Yao, Jianguo; Liu, Xue; Zhu, Guchuan; Sha, Lui. NetSimplex: Controller Fault Tolerance Architecture in Networked Control Systems. // IEEE Transactions on Industrial Informatics. 9, 1(2013), pp. 346-356. DOI: 10.1109/TII.2012.2219060

[15] Mao, Zehui; Jiang, Bin; Shi, Peng. Observer-based faulttolerant control for a class of networked control systems with transfer delays. // Journal of the Franklin Institute. 348, (2011), pp. 763-776. DOI: 10.1016/j.jfranklin.2011.02.004

[16] Aberkane, Samir; Sauter, Dominique; Ponsart, Jean Christophe. Output-Feedback $\mathrm{H} \infty$ Control of a Class of Networked Fault Tolerant Control Systems. // IEEE Mediterranean Conference on control and Automation/ Athens, Greece, 2007, pp. 1-6.

[17] Moradi Amani, A.; Afshar, A.; Menhaj, M. B. Fault Tolerant Control of Networked Control System in presence of Actuator Failure using Predictive Reconfiguration. // 2009 IEEE International Conference on Control and Automation/Christchurch, New Zealand, 2009, pp. 477482. DOI: 10.1109/ICCA.2009.5410333

[18] Yao, Lina; Peng, Bo. Fault diagnosis and fault tolerant control $f$ or the non-Gaussian time-delayed stochastic distribution control system. // Journal of the Franklin Institute. 351, (2014), pp. 1577-1595. DOI: 10.1016/j.jfranklin.2013.11.009

[19] Tian, Engang; Yue, Dong; Cheng Yang, Tai; Gu, Zhou; Lu, Guoping. T-S Fuzzy Model-Based Robust Stabilization for Networked Control Systems with Probabilistic Sensor and Actuator Failure. // IEEE Transactions on Fuzzy Systems. 19, 3(2011), pp. 553-561. DOI: 10.1109/TFUZZ.2011.2121069

[20] Yin, Zuoyou; Kang, Yunxia; Chang, Xiaoheng; Lun, Shuxian. Robust H-infinity Fault Tolerant Control for a Class of Nonlinear networked control Systems Based on TS Fuzzy Model. // 24th Chinese Control and Decision Conference (CCDC)/2012, pp. 2292-2296. DOI: 10.1109/ccdc.2012.6244366

[21] Mao, Zehui; Jiang, Bin; Shi, Peng; Cocquempot, Vincent. High Gain Observer-based Fault Estimation for Nonlinear Networked Control Systems. // 2008 American Control Conference/Westin Seattle Hotel, Seattle, Washington, USA, 2008, pp. 3058-3063.

[22] Mao, Zehui; Jiang, Bin; Shi, Peng. Observer based faulttolerant control for a class of nonlinear networked control systems. // Journal of the Franklin Institute. 347, (2010), pp. 940-956. DOI: 10.1016/j.jfranklin.2010.01.007

[23] Hu, S.; Yue, D.; Du, Z.; Liu, J. Reliable H1 non-uniform sampling tracking control for continuous-time non-linear systems with stochastic actuator faults. // IET Control Theory and Applications. 6, 1(2012), pp. 120-129. DOI: 10.1049/iet-cta.2010.0700

\section{Authors' addresses}

Liu Xiuzhi, Ph.D.

1) School of automation, Beijing Institute of Technology, 5 South Zhongguancun Street, Haidian District, Beijing, Postcode: 100081, China

E-mail:1_xiuzhi@sina.com

2) College of Electrical Engineering and automation, Shandong University of Science and Technology, Qingdao, Shandong 266590, China

Dai Yaping, Professor

School of automation, Beijing Institute of Technology, 5 South Zhongguancun Street, Haidian District, Beijing, Postcode: 100081, China

E-mail:daiyaping@bit.edu.cn 